\title{
Recognition and Binding of Aliphatic Dicarboxylic Acids C4 - C10 by Diiminocalix[4]arene
}

\author{
Olga Kalchenko ${ }^{1}$, Andrew Solovyov ${ }^{1,2}$, Vitaly Kalchenko ${ }^{1}$ \\ ${ }^{1}$ Institute of Organic Chemistry National Academy of Sciences of Ukraine, \\ Murmanska str., 5, Kyiv-94, 02660, Ukraine \\ ${ }^{2}$ Present address: Department of Chemical \& Biomolecular Engineering, University of California, \\ Berkeley, USA, CA 94720-1460 \\ oik@ioch.kiev.ua
}

Keywords: calix[4]arenes, reversible-phase high performance liquid chromatography, aliphatic dicarboxylic acids, Host-Guest inclusion complexes, supramolecular interactions, binding constants.

Host-Guest complexation of 5,17-bis-(N-tolyliminomethyl)-25,27-dipropoxycalix[4]arene with aliphatic dicarboxylic acids $\mathrm{C} 4-\mathrm{C} 10$ has been studied in water-organic solution by the RP HPLC and molecular modeling methods. The stability constants $\left(\log K_{A}=2.56-3.05\right)$ of the supramolecular complexes are depended on structure, $p K a$ and $\log P$ values of the acids. The complexation is determined by the hydrogen bonds of the $\mathrm{COOH}$ group of the dicarboxylic acids with nitrogen atoms at the upper rim or oxygen atoms at the lower rim of the calixarene.

\section{Introduction}

Molecular recognition and binding of bio active compounds by artificial receptors constitute an important problem in chemistry and biology [1].

Calixarenes [2] bearing preorganized binding groups at the upper or the lower rim of macrocycle recognize different bio relevant molecules or iones and simulate substratereceptor interactions in bio-chemical processes $[3,4]$. The receptor properties of the functionalized calixarenes toward the bio active molecules make them promising materials for sensor technologies [5-7] and for drug delivery systems in pharmaceutical science $[8,9]$.

Formerly it was shown that the functionalized calix[4]arenes are effective receptors for aromatic carboxylic acids [10]. The aim of this work is investigation of the Host-Guest complexation of the 5,17-bis-(Ntolyliminomethyl)-25,27-dipropoxycalix[4]arene (CA) with the aliphatic dicarboxylic acids C4 - C10 1-6 (Figure 1). 


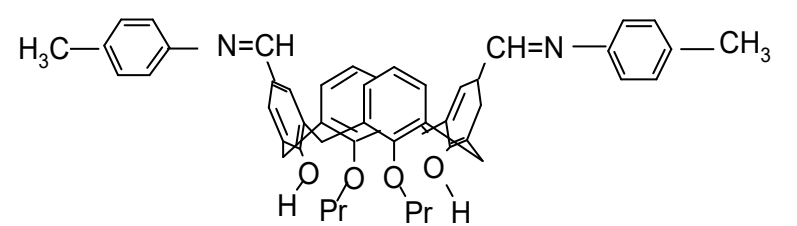

\section{CA}

1: $\mathrm{HOOC}-\left(\mathrm{CH}_{2}\right)_{2}-\mathrm{COOH}$

2: $\mathrm{HOOC}-\left(\mathrm{CH}_{2}\right)_{3}-\mathrm{COOH}$

3: $\mathrm{HOOC}-\left(\mathrm{CH}_{2}\right)_{4}-\mathrm{COOH}$

4: $\mathrm{HOOC}-\left(\mathrm{CH}_{2}\right)_{6}-\mathrm{COOH}$

5: $\mathrm{HOOC}-\left(\mathrm{CH}_{2}\right)_{7}-\mathrm{COOH}$

6: $\mathrm{HOOC}-\left(\mathrm{CH}_{2}\right)_{8}-\mathrm{COOH}$

Figure 1. Calix[4]arene CA and succinic 1, glutaric 2, adipic 3, suberic 4, azelaic 5, sebacic 6 dicarboxylic acids.

Reversible-phase high-performance liquid chromatography method (RP HPLC) was used for determination of the stability constants of the Host-Guest supramolecular complexes formed.

\section{Experimental part}

\section{Reagents}

CA was synthesized by the method [11]. Methanol and acetic acid were obtained from the Acros Organics (Thermo Fisher Scientific, New Jersey, USA). Dicarboxylic acids were purchased from Sigma-Aldrich (SigmaAldrich Corporation, USA).

\section{RP HPLC analysis}

RP HPLC analysis was performed on the high pressure liquid chromatograph Hitachi (Hitachi, Ltd., Tokyo, Japan) in isocratic conditions using the column Zorbax CN (Sigma-Aldrich) as a stationary phase. The calixarene based mobile phase was prepared by dissolving of the $\mathbf{C A}$ in the mixture $\mathrm{H}_{2} \mathrm{O} / \mathrm{MeOH} / \mathrm{CH}_{3} \mathrm{COOH} \quad(94 / 5 / 1 \quad \mathrm{v} / \mathrm{v})$. The calixarene concentration in the mobile phase were $0.05-0.6 \mathrm{mM}$. A volume of the sample injected was $20 \mu \mathrm{L}$. All chromatograms were obtained at $26{ }^{\circ} \mathrm{C}$. UV detector was operated at $210 \mathrm{~nm}$ and the flow rate was $0.8 \mathrm{ml} / \mathrm{min}$.

\section{Molecular modeling}

The molecular modeling of the CA complexes with the acids was carried out by molecular mechanics $\mathrm{MM}+$ method, force field PM3 (software package Hyper Chem, version 8) [12]. RMS gradient was $0.01 \mathrm{kcal} / \mathrm{mol}$.

\section{Results and Discussion}

For the stability constants determination of the calixarene Host-Guest inclusion complexes with organic molecules NMR, UV-Vis, fluorescent, calorimetry methods are used. In some cases due to poor solubility of the calixarenes or the Guest molecules or the absence of a corresponding instrumental response on the complexation process the above mentioned methods are inefficient. To solve such problem the RP HPLC method for the determination of 


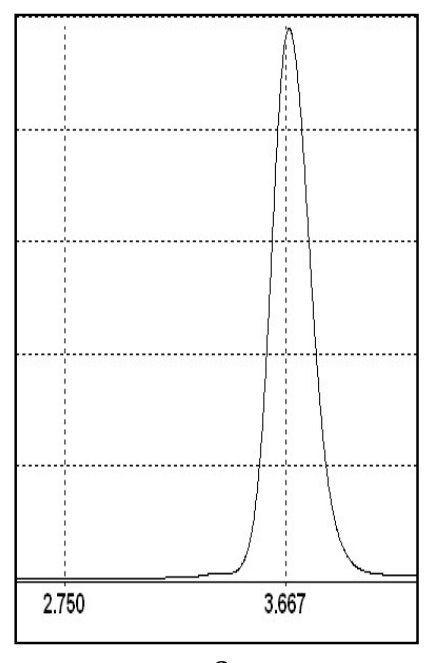

a
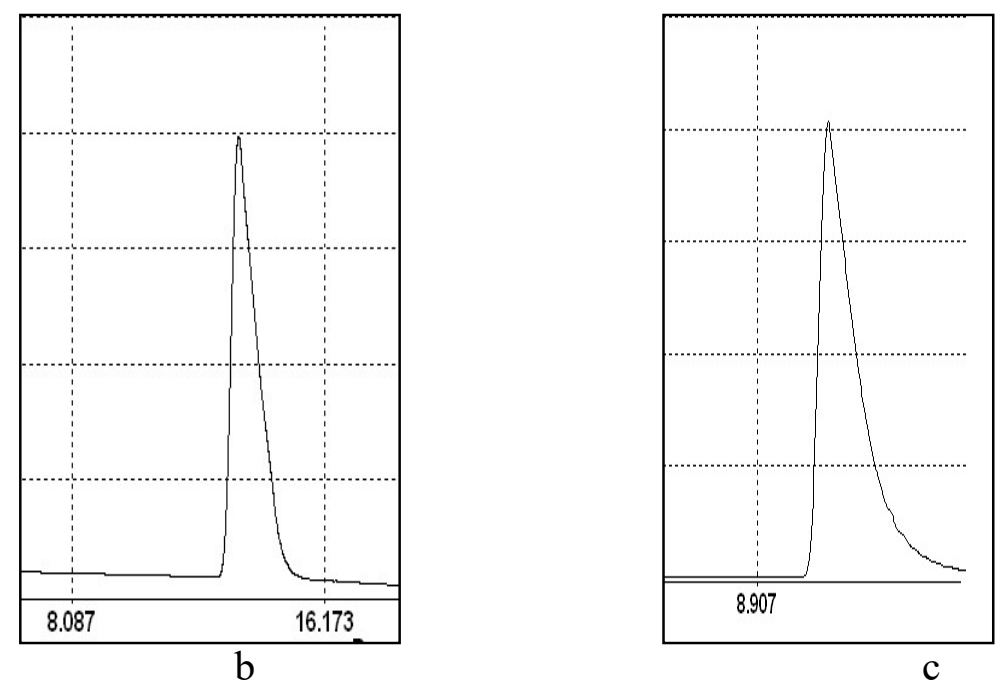

Figure 2. The chromatogram of CA (a) and the chromatograms of the adipic acid $\mathbf{3}$ before (b) and after (c) $\mathbf{C A}$ addition in the mobile phase.

stability constants of the calixarene complexes with organic compounds in water or waterorganic solutions was developed $[13,14]$. The method is based on a determination of the capacity coefficient $k^{\prime}$ of the Guest molecule before and after calixarene addition to the mobile phase. The stability constant $K_{A}$ of the calixarene complex with the Guest molecule (for 1:1 stoichiometry) can be calculated by equation (1):

$$
1 / k^{\prime}=1 / k_{0}{ }^{\prime}+K_{A} \times[\mathrm{CA}] / k_{0}{ }^{\prime}
$$

where $k_{0}$ ' and $k^{\prime}$ are capacity coefficients of the Guest molecule determined in the absence and the presence of the calixarene in the mobile phase.

The HPLC investigation of complexation of calixarene CA with the dicarboxylic acids 1-6 was performed in solution $\mathrm{H}_{2} \mathrm{O} / \mathrm{MeOH} / \mathrm{CH}_{3} \mathrm{COOH} \quad 94 / 5 / 1 \quad \mathrm{v} / \mathrm{v}$ using Zorbax CN column. The conditions (the solvent and the stationary phase) provide a good solubility of the Host and the Guest and their sharp peaks on the chromatograms (Figure 2). Linear adsorption isotherm of $\mathbf{C A}$ $(r=0.99)$ is indicated on its reversible sorption on the support.

An addition of $\mathbf{C A}$ to the mobile phase decreases the capacity coefficient $k$ ' of the acids (Figure 3).

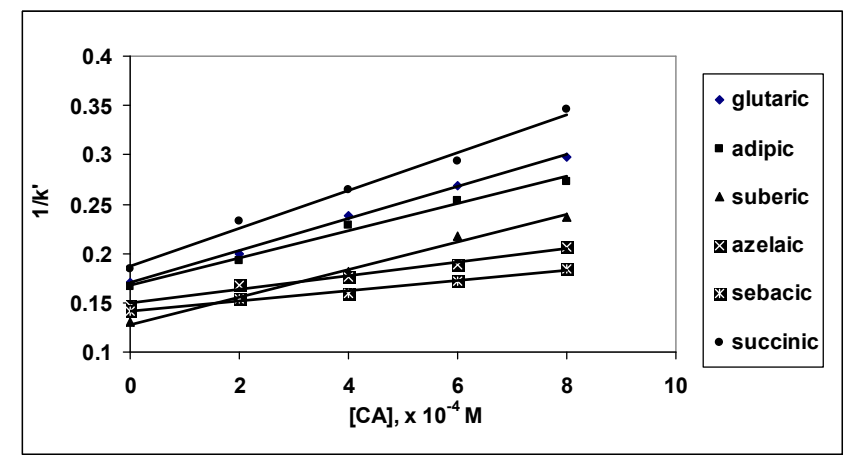

Figure 3. Plots of the $1 / k^{\prime}$ vs the $\mathbf{C A}$ concentration $(r=0.99)$.

The linear character plots of $k^{\prime} v s$ the CA concentration (Figure 3) testifies the formation of the Host-Guest inclusion complexes with 1:1 stoichiometry and allows 
the correct calculation $K_{A}$ values by the equation (1).

The stability constants $K_{A}$ and free Gibbs energy $\Delta G\left(\Delta G=-R T \ln K_{A}\right)$ for the $\mathbf{C A}$-acid complexes are presented in Table $\mathbf{1 .}$

Table 1. Stability constants $\log K_{A}(\mathrm{RSD}=3-6 \%)$, free Gibbs energy $\Delta G(\mathrm{~kJ} / \mathrm{Mol})$ of the complexes, $\log P$ and $p K a$ of the acids 1-6

\begin{tabular}{|c|c|c|c|c|}
\hline Acid & $\begin{array}{c}\text { lo } \\
\mathrm{g} \\
K \\
A\end{array}$ & $\Delta G$ & $\begin{array}{c}\log \\
P\end{array}$ & $\begin{array}{c}p K \\
a\end{array}$ \\
\hline $\begin{array}{c}\text { Succinic } \\
\mathbf{1}\end{array}$ & $\begin{array}{l}3 . \\
0 \\
5\end{array}$ & $\begin{array}{c}- \\
17 . \\
39\end{array}$ & $\begin{array}{c}- \\
0.4 \\
0\end{array}$ & $\begin{array}{c}4.2 \\
1\end{array}$ \\
\hline $\begin{array}{c}\text { Glutaric } \\
\mathbf{2}\end{array}$ & $\begin{array}{l}2 . \\
9 \\
6\end{array}$ & $\begin{array}{c}- \\
16 . \\
88\end{array}$ & $\begin{array}{c}- \\
0.2 \\
9\end{array}$ & $\begin{array}{c}4.3 \\
2\end{array}$ \\
\hline Adipic 3 & $\begin{array}{l}2 . \\
9 \\
4\end{array}$ & $\begin{array}{c}- \\
16 . \\
73\end{array}$ & $\begin{array}{c}0.1 \\
0\end{array}$ & $\begin{array}{c}4.4 \\
1\end{array}$ \\
\hline Suberic 4 & $\begin{array}{l}2 . \\
9 \\
3\end{array}$ & $\begin{array}{c}- \\
16 . \\
67\end{array}$ & $\begin{array}{c}1.3 \\
8\end{array}$ & $\begin{array}{c}4.5 \\
2\end{array}$ \\
\hline Azelaic 5 & $\begin{array}{l}2 . \\
7 \\
4\end{array}$ & $\begin{array}{c}- \\
15 . \\
61\end{array}$ & $\begin{array}{c}1.5 \\
7\end{array}$ & $\begin{array}{c}4.5 \\
3\end{array}$ \\
\hline Sebacic 6 & $\begin{array}{c}2 . \\
5 \\
6\end{array}$ & $\begin{array}{c}- \\
14 . \\
59\end{array}$ & $\begin{array}{c}2.2 \\
0\end{array}$ & $\begin{array}{c}4.5 \\
9\end{array}$ \\
\hline
\end{tabular}

The stability constants are depended on number of carbon atoms in aliphatic chain of the acids and linearly increase from $\log K_{A}$ 2.56 (sebacic acid 6) to $\log K_{A} 3.05$ (succinic acid 1). Decreasing of length of the acids chain increases the stability constants of the complexes (Table 1 and Figure 4).

The calixarene Host-Guest complexes can be stabilized by hydrogen bonds formed between carboxyl groups of the acids and nitrogen or oxygen atoms at the upper or the lower rim of the calixarene, Van der Waals, and hydrophobic interactions. Role of the hydrophobic interactions in the complexation is confirmed by correlation of the stability constants $K_{A}$ with the lipophilicity $\log P$ values of the dicarboxylic acids [15-18] (Figure 5).

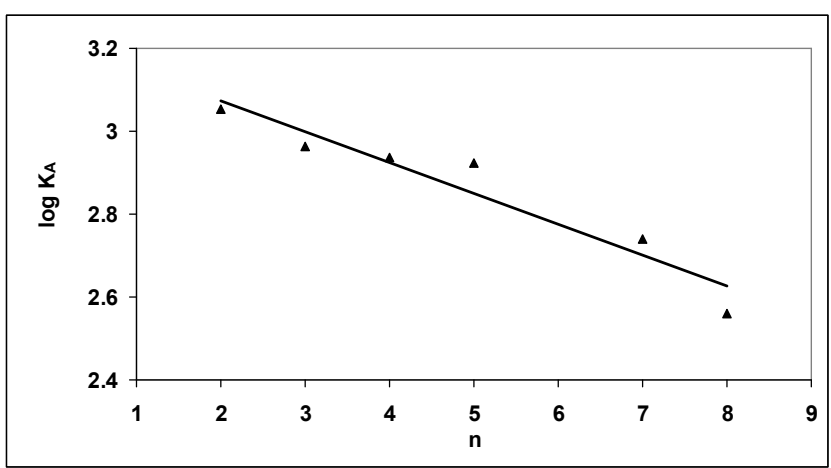

Figure 4. Plots of the $\log K_{A} v s$ the number of carbon atoms in aliphatic chain of acids 1-5 $(y=-$ $0.0857 \mathrm{x}+3.1856 ; \mathrm{r}=0.96)$.

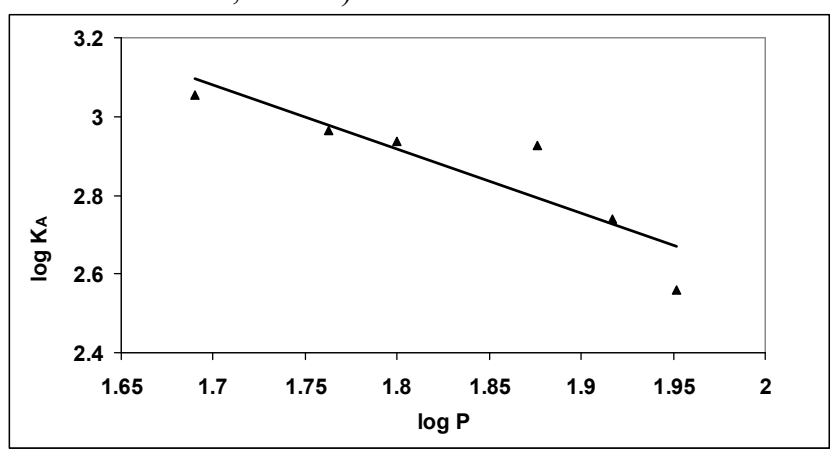

Figure 5. Plots $\log K_{A} v s \log P$ of acids 1-6 $(\mathrm{y}=-0.1454 \mathrm{x}$ $+2.974 ; \mathrm{r}=0.88)$. 


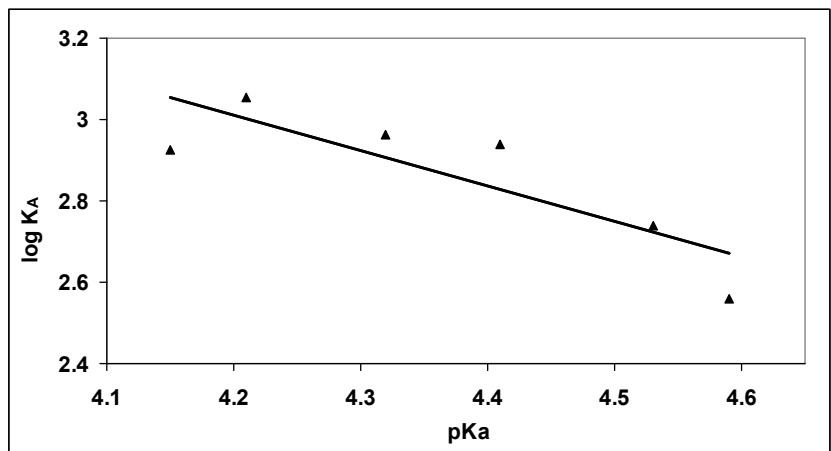

Figure 6. Plots of $\log K_{A}$ vs $p K a$ of acids 1-6 ( $\mathrm{y}=-$ $1.0464 \mathrm{x}+7.498 ; \mathrm{r}=0.84)$.

An increasing of the $\log P$ values of the acids decreases the $\log K_{A}$ values of their complexes (Figure 5).

The stability constants $\left(\log K_{A}\right)$ are dependent on the $p K a$ values $[19,20]$ of the dicarboxylic acids (Figure 6).

Decreasing of the acid's $p K a$ increases the $K_{A}$ of the complexes (Figure 6).

To clarify the nature of the Host-Guest interaction the molecular modeling of the $\mathbf{C A}$ complexes with succinic acid $\mathbf{1}$ was performed (Figure 7).

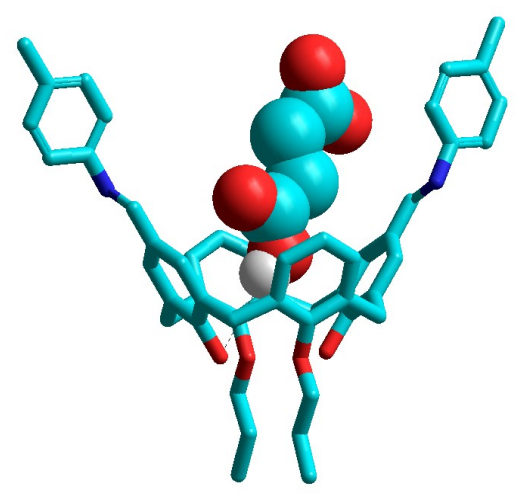

A

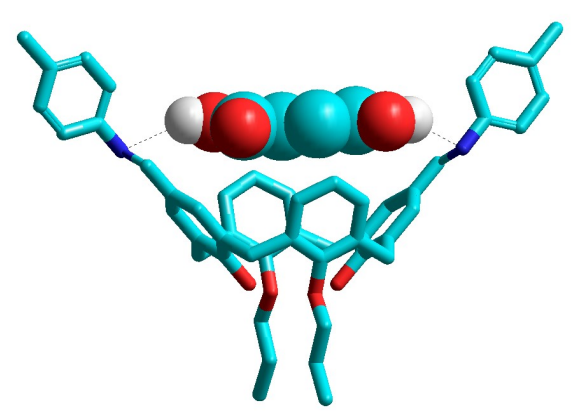

B

Figure 7. Energy minimized structures of the oxygenbonded complex $\mathbf{A}$ and the nitrogen-bonded complex $\mathbf{B}$ of CA with succinic acid $\mathbf{1}$.

The complexes are stabilized by the hydrogen bonds of $\mathrm{COOH}$ groups of the acid with nitrogen or oxygen atoms of the CA molecule. Succinic acid $\mathbf{1}$ forms two types of the complexes. One of them $\mathbf{A}$ is stabilized by the hydrogen bond with the oxygen atom of $\mathrm{OH}$ group at the CA lower rim (O-H $\cdots \mathrm{O}$ distance 3.02 Á). The second complex $\mathbf{B}$ is stabilized by two hydrogen bonds with distal nitrogen atoms at the upper rim $\left(\mathrm{O}-\mathrm{H}^{\cdots} \mathrm{N}\right.$ distances 2.61 Á). Complex B is more stable compared with A. Differences between calculated energies $\Delta \Delta \mathrm{E}$ of the complexes are $5.15-6.44 \mathrm{~kJ} / \mathrm{mol}$. 
Table 2. $\Delta \Delta \mathrm{E}$ values $(\mathrm{kJ} / \mathrm{mol})$ between $\mathbf{B}$ and $\mathbf{A}$ types of the $\mathbf{C A}$-acid complexes

\begin{tabular}{|c|c|c|}
\hline Acid & $\mathrm{n}^{*}$ & $\Delta \Delta \mathrm{E}, \mathrm{kJ} / \mathrm{mol}$ \\
\hline Succinic 1 & 2 & 6.44 \\
\hline Glutaric 2 & 3 & 6.57 \\
\hline Adipic 3 & 4 & 6.03 \\
\hline Suberic 4 & 5 & 6.36 \\
\hline Azelaic 5 & 7 & 5.36 \\
\hline Sebacic 6 & 8 & 5.15 \\
\hline
\end{tabular}

*Number of carbon atoms in aliphatic chain of acids 1-6

An increasing in the length of the dicarboxylic acid molecule destabilizes the nitrogen-bonded complexes of type B. This is confirmed by decreasing of the calculated values of $\Delta \Delta \mathrm{E}$ for the nitrogen-bonded $\mathbf{B}$ and the oxygen-bonded A complexes $v s$ the number of carbon atoms in aliphatic chain of acids 1-6 ( Table 2 and Figure 8). At the same time, the lengths of the hydrogen bonds $\mathrm{O}-\mathrm{H}^{\cdots} \mathrm{N}$ are increasing from $2.61 \AA ̊$ to $3.12 \AA$.

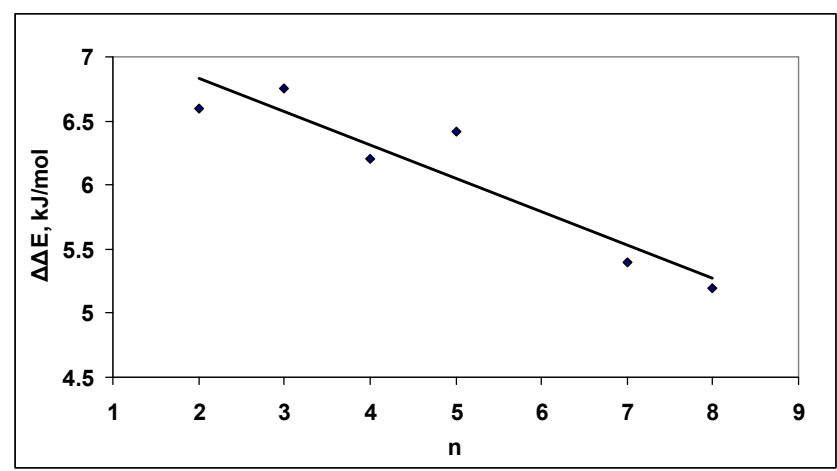

Figure 8. Plots of $\Delta \Delta \mathrm{E}$ values of the complexes $\mathbf{B}$ and A vs number of carbon atoms (n) in aliphatic chain of acids 1-6 $(\mathrm{y}=-0.2358 \mathrm{x}+7.1229 ; \mathrm{r}=0.92)$

\section{Conclusions}

CA decorated with two proton acceptor imino groups at the upper rim of the macrocycle forms stable supramolecular Host-Guest complexes with aliphatic dicarboxylic acids in water solutions. The stability constants of the CA complexes determined by RP HPLC method are depended on the number of carbon atoms, $\log P$ and $p K a$ of the acids, and are in the region from $\log K_{A} 2.56$ (sebacic acid 6) to $\log K_{A} \quad 3.05 \quad$ (succinic acid 1). Molecular modeling shows that the inclusion complexes are stabilized by the intermolecular hydrogen bonds of $\mathrm{COOH}$ groups with nitrogen atoms at the upper rim or with oxygen atom at the lower rim of the calixarene.

\section{Acknowledgements}

This work was supported by the State Fund for Fundamental Researches of Ukraine.

\section{References}

[1] Persch E., Dumele O., Diederich F. Molecular recognition in chemical and biological systems. Angew. Chem. Int. Ed. 2015; 54: 3290-3327.

[2] Gutsche C.D.: Calixarenes revisited. Cambridge: RSC.; 1998.

[3] Sansone F., Segura M., Ungaro R. Calixarenes in bioorganic and biomimetic chemistry. In: Asfari M.-Z., Böhmer V., Harrowfield J., Vicens J., (eds.). Calixarenes 2001. Dordrecht: Kluwer Academic Publishers; 2001, pp. 496. 
[4] Casnati A., Sansone F., Ungaro R. Peptido- and Glycocalixarenes: $\alpha$-Playing with hydrogen bonds around hydrophobic cavities. Acc. Chem. Res. 2003; 36: 246-254.

[5] Diamond D., Nolan K. Calixarenes: designer ligands for chemical sensors. Anal. Chem. 2001; 73: 22A-29A.

[6] Coleman A.W., Perret F., Moussa A., Dupin M., Guo Y., Perron H. Calix[n]arenes as protein sensors. Top. Curr. Chem. 2007; 277: 31-88.

[7] Kalchenko O.I., Lipkowski J., Kalchenko V. Chromatography in supramolecular and analytical chemistry of calixarenes. In: J. Atwood, L.Barboor (eds.). Comprehensive supramolecular chemistry II, Elsevier, 2017, 239-261.

[8] Rodik R.V., Boyko V.I., Kalchenko V.I. Calixarenes in bio-medical researches. Curr. Med. Chem. 2009; 16: 1630-1655.

[9] de Fatima A., Fernandes S.A., Sabino A.A. Calixarenes as new platforms for drug des ign. Curr. Drug Discovery Technol. 2009; 6: 151-170.

[10] Kalchenko O.I., Cherenok S.A., Kalchenko V.I., Solovyov A.V., Gorbatchuk V.V. Study of the complexation of 5,17-bis-(N-tolylimino- methyl)25,27-dipropoxycalix [4] arene with benzoic acids. J. Org. and Pharm. Chem. 2013; 11: 3-8.

[11] Solovyov A.V., Cherenok S., Tsymbal I., Failla S., Consiglio G., Finocchiaro P., Kalchenko V.I. Calix[4]arenes bearing alpha-amino- or alphahydroxyphosphonic acid fragments at the upper rim. Heteroatom Chemistry. 2001;12: 58-67.

[12] http://www.hyper.com/Download/All Downloads/tabid/470/Default.aspx

[13]Lipkowski J., Kalchenko O.I., Slowikowska J., Kalchenko V.I., Lukin O.V., Markovsky L.N., Nowakowski R. Host-Guest interactions of calix[4]resorcinarenes with benzene derivatives in conditions of reversed-phase high-performance liquid chromatography. Stability constants determination. J. Phys. Org. Chem. 1998; 11: 426435.

[14]Kalchenko O.I., Lipkowski J., Kalchenko V.I., Vysotsky M.A., Markovsky L.N. Effect of octakis(diethoxyphosphoryloxy)-tert-butylcalix[8]arene in mobile phase on the reversedphase retention behavior of aromatic compounds. Host-Guest complexes formation and the stability constants determination. J. Chrom. Sci. 1998; 36: 269-273.

[15] Hansch C., Leo A., Hoekman D.H. Exploring QSAR: hydrophobic, electronic, and steric constants (ACS Professional Reference Book). American Chemical Society, Medical.; 1995.

[16] www.chemspider.com/ChemicalStructure.191.html.

[17]www.drugbank.ca/drugs/db07645.

[18] www.chemspider.com/ChemicalStructure.844.html.

[19] Serjeant E.P., Dempsey B., Ionization constants of organic acids in aqueous solution. Oxford: Pergamon.; 1979.

[20] Sober H.A., Ed., pKa Prediction for organic acids and bases, Handbook of biochemistry. Boca Raton: FL CRC Press.; 1968. 